\title{
Afrobatrachian mitochondrial genomes: genome reorganization, gene rearrangement mechanisms, and evolutionary trends of duplicated and rearranged genes
}

Atsushi Kurabayashi ${ }^{*}$ and Masayuki Sumida

\begin{abstract}
Background: Mitochondrial genomic (mitogenomic) reorganizations are rarely found in closely-related animals, yet drastic reorganizations have been found in the Ranoides frogs. The phylogenetic relationships of the three major ranoid taxa (Natatanura, Microhylidae, and Afrobatrachia) have been problematic, and mitogenomic information for afrobatrachians has not been available. Several molecular models for mitochondrial (mt) gene rearrangements have been proposed, but observational evidence has been insufficient to evaluate them. Furthermore, evolutionary trends in rearranged $\mathrm{mt}$ genes have not been well understood. To gain molecular and phylogenetic insights into these issues, we analyzed the mt genomes of four afrobatrachian species (Breviceps adspersus, Hemisus marmoratus, Hyperolius marmoratus, and Trichobatrachus robustus) and performed molecular phylogenetic analyses. Furthermore we searched for two evolutionary patterns expected in the rearranged $\mathrm{mt}$ genes of ranoids.
\end{abstract}

Results: Extensively reorganized $\mathrm{mt}$ genomes having many duplicated and rearranged genes were found in three of the four afrobatrachians analyzed. In fact, Breviceps has the largest known mt genome among vertebrates. Although the kinds of duplicated and rearranged genes differed among these species, a remarkable gene rearrangement pattern of non-tandemly copied genes situated within tandemly-copied regions was commonly found. Furthermore, the existence of concerted evolution was observed between non-neighboring copies of triplicated 125 and 165 ribosomal RNA regions.

Conclusions: Phylogenetic analyses based on mitogenomic data support a close relationship between Afrobatrachia and Microhylidae, with their estimated divergence 100 million years ago consistent with present-day endemism of afrobatrachians on the African continent. The afrobatrachian $\mathrm{mt}$ data supported the first tandem and second non-tandem duplication model for $\mathrm{mt}$ gene rearrangements and the recombination-based model for concerted evolution of duplicated $\mathrm{mt}$ regions. We also showed that specific nucleotide substitution and compositional patterns expected in duplicated and rearranged $\mathrm{mt}$ genes did not occur, suggesting no disadvantage in employing these genes for phylogenetic inference.

Keywords: Mitochondrial genome, Gene rearrangement, Concerted evolution, Substitution rate, Selection, Afrobatrachia, Ranoides

\footnotetext{
* Correspondence: kuraba@hiroshima-u.ac.jp

Institute for Amphibian Biology, Graduate School of Science, Hiroshima University, 739-8526 Hiroshima, Japan
}

\section{() Biomed Central}

(c) 2013 Kurabayashi and Sumida; licensee BioMed Central Ltd. This is an Open Access article distributed under the terms of the Creative Commons Attribution License (http://creativecommons.org/licenses/by/2.0), which permits unrestricted use, distribution, and reproduction in any medium, provided the original work is properly cited. 


\section{Background}

Animal mitochondrial (mt) genomes typically consist of a closed circular molecule 16-17 kilo base pairs (kbp) in size, with multiple copies existing in every cell [1]. Most animal mt genomes contain the same 37 genes: $12 \mathrm{~S}$ and $16 \mathrm{~S}$ ribosomal RNA genes (12S and $16 \mathrm{~S}$ rrns), 22 transfer RNA genes (trns), and 13 protein-coding genes (ATPase subunits 6 and 8: atp6 and 8; cytochrome oxidase subunits I, II and III: co1-3; cytochrome $b$ apoenzyme: $c y t b$; and nicotinamide adenine dinucleotide dehydrogenase subunits 1-6 and 4 L: nd1-6 and $4 L$ ) [2,3]. Of these 37 genes, 28 are encoded on the heavier guanine-rich DNA strand ( $\mathrm{H}$-strand), while nine are encoded on the cytosine-rich light strand (L-strand). Vertebrate mt genomes also contain a long non-coding region (approximately 0.5-9 kb; [4]) called the control region (CR, or the D-loop region), which includes the signals for regulating mtDNA transcription and the replication origin of the $\mathrm{H}$-strand $\left(\mathrm{O}_{\mathrm{H}}\right)$ (e.g., $[5,6])$. A short non-coding replication origin for the $\mathrm{L}$-strand $\left(\mathrm{O}_{\mathrm{L}}\right)$ has also been identified in the $\mathrm{mt}$ genomes of most vertebrates, excluding birds [2,5,7].

Nucleotide substitution rates within $\mathrm{mt}$ genes are widely accepted to be much faster than in the nuclear genome, and the $37 \mathrm{mt}$ genes generally have different substitution rates from one another [8-10]. Because of their high copy numbers and fast and/or multiple nucleotide substitution rates, mitogenomic sequences have been widely used in genetic and evolutionary studies (e.g., [11]). Nearly $70 \%$ of molecular phylogenetic studies on animal taxa have used mt gene data [12].

Mitochondrial gene arrangements tend to be conserved within vertebrates, with all 37 genes and the CR organized in relatively the same order in taxa from teleost fishes to eutherian mammals (e.g., [2]). However, rearranged $\mathrm{mt}$ genomes have been found in some taxa of all major vertebrate groups (fishes, amphibians, reptile, birds, and mammals (e.g., $[2,13]))$. Because the animal $\mathrm{mt}$ genome has no introns and very few intergenic spacers and is assumed to lack recombination (e.g., [1,14]), rearrangements of its genes have usually been interpreted to be the result of tandem duplication caused by replication errors, e.g., the tandem duplication and random loss (TDRL) model $[15,16]$. However, recent evidence for recombination in the animal $\mathrm{mt}$ genome compels the reconsideration of several other hypothesized duplications and gene rearrangements [11,17-22]. Consequently several gene rearrangement modes mediated by recombination have been proposed [4,23-26].

Two alternative concerted evolution models, based on duplication and recombination mechanisms, have also been proposed to explain nearly-identical nucleotide sequences occasionally found between duplicated CRs [27]. However, observational evidence to validate these models is still insufficient because of the rarity of $\mathrm{mt}$ genomes having intermediate conditions in the gene rearrangement process (but see $[4,13,26,28,29])$. Furthermore, different nucleotide substitution trends, such as the relaxation of purifying pressure and accompanying substitution rate acceleration, have been suspected for (nuclear) duplicated genes (e.g., [30,31]). Also a regionspecific nucleotide compositional bias possibly affecting the rearranged genes has been reported from vertebrate $\mathrm{mt}$ genomes (e.g., [32-34]).

Substitution-rate and nucleotide-compositional heterogeneities among lineages are well known to cause phylogenetic artifacts (e.g., [35-37]). Therefore, many phylogeneticists are particularly interested in knowing how marker genes evolve [38]. Unfortunately, the evolutionary trends of duplicated and rearranged $\mathrm{mt}$ genes in animals have not been well investigated because of their low numbers and, especially, because very few examples exist of rearranged and non-rearranged $\mathrm{mt}$ genomes within closely-related taxa. Thus, an understanding of the patterns and mechanisms of mitogenomic duplications and rearrangements and the evolutionary trends of the resulting genes could be fostered by analyzing an animal group with (1) differential frequencies of genome rearrangements among lineages and (2) intermediate states of the genomic rearrangement process. Among vertebrates, anurans (especially Ranoides; see below) are good candidates to meet these conditions.

Generally two major anuran groups, Archaeobatrachia and Neobatrachia, are recognized. The former is regarded as a paraphyletic assemblage of basal anurans (e.g., [39]). The latter is a monophyletic taxon of modern anurans and contains over 95\% of extant frogs [40-42]. The mt gene arrangements of almost all archaeobatrachians so far reported (excluding the Leiopelma archeyi $\mathrm{mt}$ genome [43]) are identical to the typical vertebrate-type arrangement (e.g., [9] and Figure 1]). However, neobatrachians commonly have a slightly modified gene arrangement (neobatrachiantype arrangement) having four trns translocations relative to the vertebrate-type arrangement (e.g., [44,45]), and Figure 1]. In addition, further gene rearrangements have been reported in some lineages of Ranoides, which comprises three major groups: Microhylidae, Natatanura, and Afrobatrachia (see Figure 2). Microhylidae (= narrowmouth toads) $\mathrm{mt}$ genomes have neobatrachian-type arrangements $[45,46]$, but large mitogenomic reorganizations involving duplications and rearrangements of protein-coding genes and CRs have been found from three distinct lineages of Natatanura (= Ranidae, sensu lato), including all members of Rhacophoroidea, part of Ranidae, and part of Dicroglossidae ([4,47-49]; and Figure 2]). Mitogenomic information has not been available for the remaining taxon, Afrobatrachia.

Afrobatrachia, endemic to Africa, consists of four families: Arthroleptidae, Hyperoliidae, Hemisotidae, and 


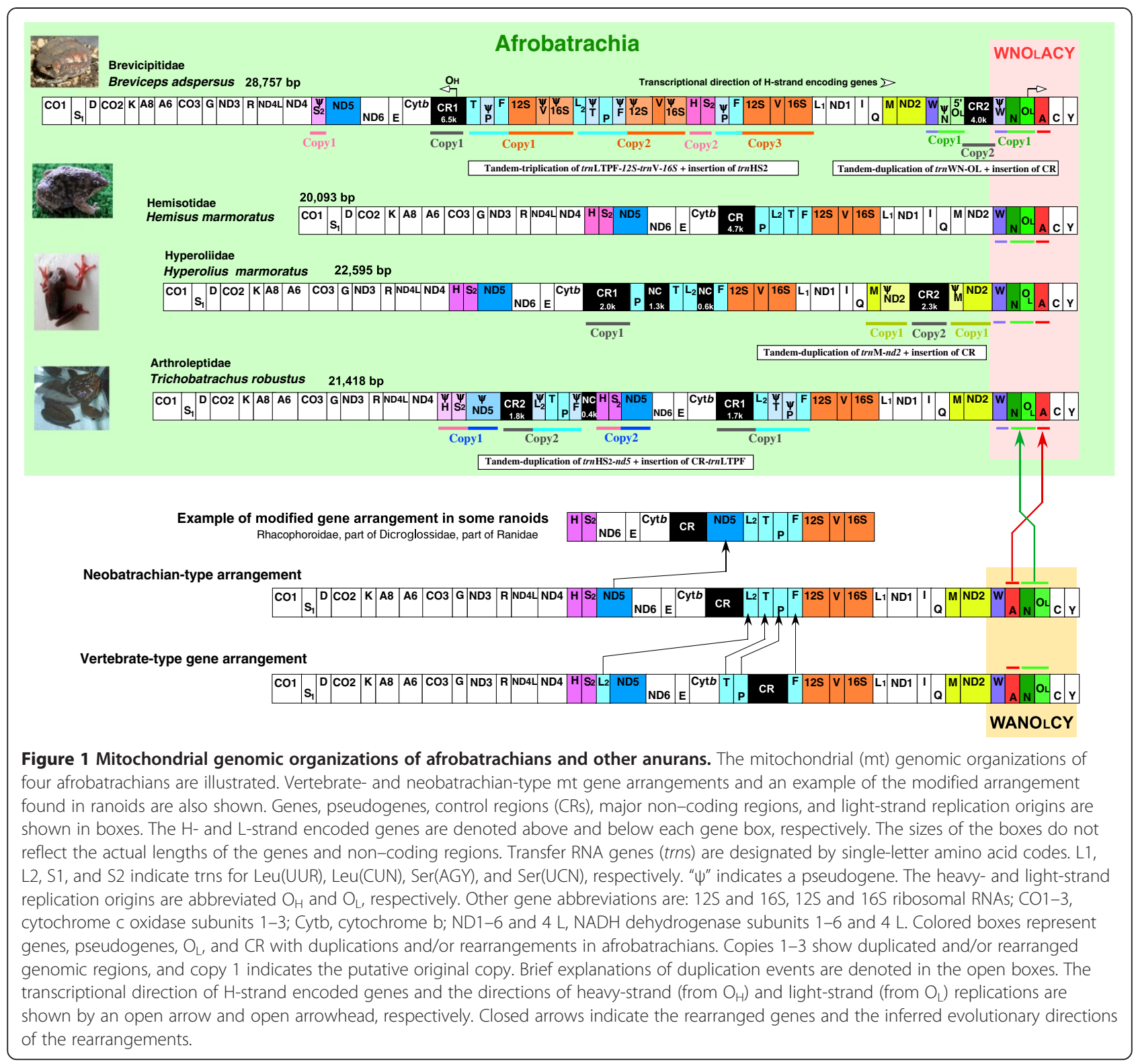

Brevicipitidae. Historically, the phylogenetic position of Hemisotidae has been problematic, and all breviciptid species were long regarded as members of Microhylidae (e.g., [40,50]). Although recent molecular phylogenetic analyses support afrobatrachian monophyly (e.g., [51,52]), clear synapomorphic characters have not been found for this group [40]. Furthermore, the phylogenetic relationships among the three major ranoid taxa have been somewhat problematic (see Results and Discussion section) and should be verified using sufficient molecular data.

In this study, we analyzed afrobatrachian mt genomes to explore the occurrence of novel mitogenomic reorganizations and to gain new insights into the mechanisms of this process. We also reviewed the phylogenetic relationships of afrobatrachians using the largest molecular dataset yet applied to this group. Finally, we tested several evolutionary trends expected in rearranged $\mathrm{mt}$ genomes and in duplicated and rearranged genes using afrobatrachian and other available ranoid mitogenomic information.

\section{Methods}

\section{Specimens used}

To sequence whole mt genomes of afrobatrachians, we used four species representing all four afrobatrachian families: Breviceps adspersus (Brevicipitidae), Hemisus marmoratus (Hemisotidae), Hyperolius marmoratus (Hyperoliidae), and Trichobatrachus robustus (Arthroleptidae). Five natatanuran species (Babina holsti and Lithobates catesbeianus, Ranidae; Buergeria buergeri, 


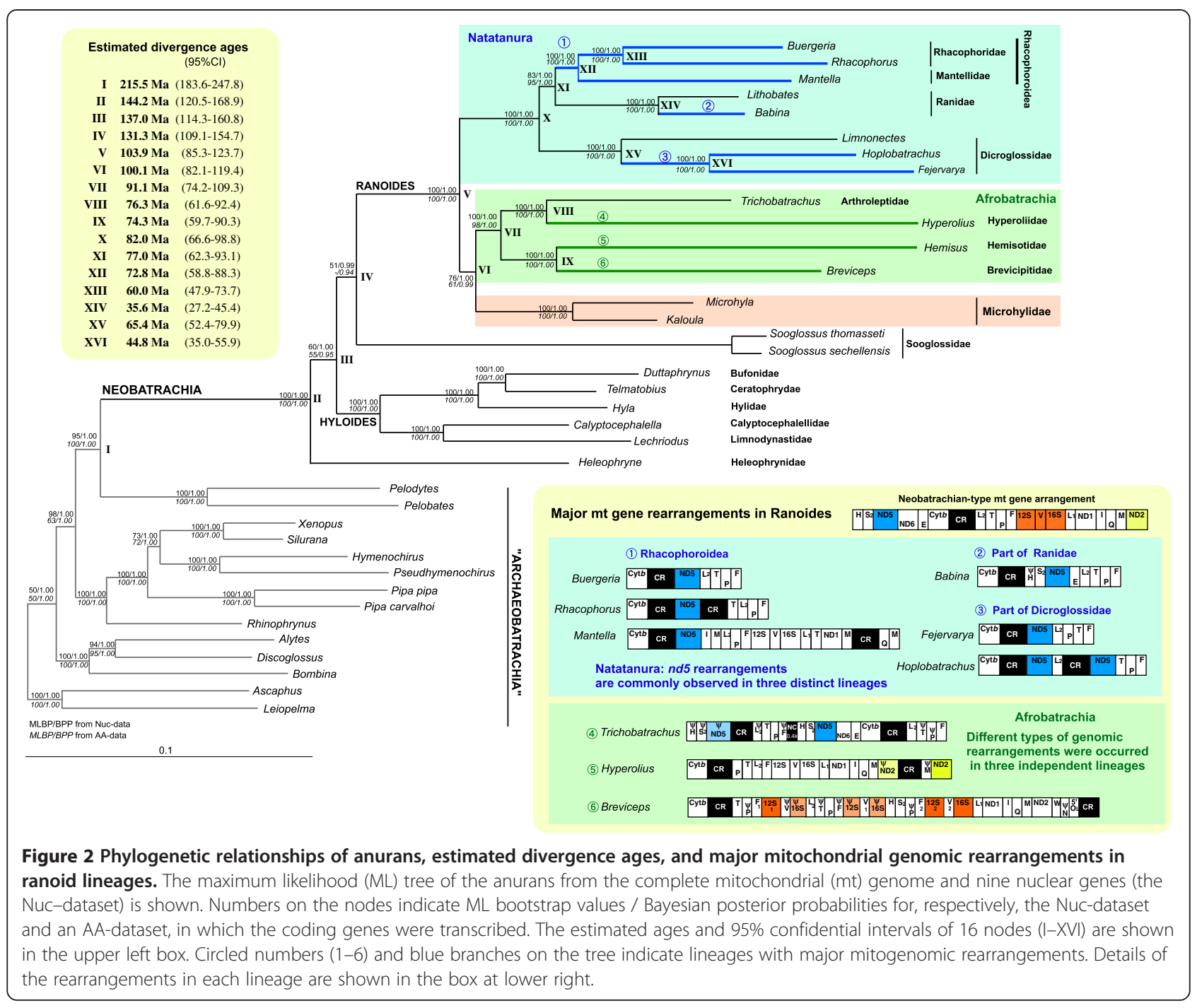

Rhacophoridae; Hoplobatrachus tigerinus and Limnonectes fujianensis, Dicroglossidae) were used to analyze their nuclear gene sequences.

Since about 2006, classifications of many frog taxa have been in a rapid state of transition. To avoid needless confusion, in this study we have basically followed the nomenclature and circumscriptions of Frost et al. [40] and Frost [41].

DNA sequencing was performed using previously extracted total DNAs [47-49,53]. Consequently, no animals were used in this study.

\section{DNA sequencing}

Whole mt genomes of the four afrobatrachians were PCR-amplified and sequenced. PCR reactions and primers have been described previously [53]. The primer-walking method was employed for sequencing using an $\mathrm{ABI}$ 3130xl automated DNA sequencer (Applied Biosystems, Foster City, CA, USA) with the BigDye Terminator Cycle Sequencing Kit (ABI). PCR fragments containing CR DNA with long tandem repeats and/or mononucleotide tracts that could not be sequenced by primer walking were subcloned into $E$. coli vector pCR-2.1 or pCR-XL using the TOPO TA Cloning Kit (Invitrogen, Carlsbad, CA, USA). To precisely sequence the long tandem repeats, a series of deleted subclones was made from the resultant subclones using the Exonuclease III deletion method [54]. The resulting $\mathrm{mt}$ gene sequences were identified by comparison with corresponding gene sequences from other vertebrates. To identify CRs, we looked for conserved sequence blocks 1, 2 and/or 3 (CSB I-III), characteristic elements of vertebrate CRs that are considered to be to be essential for the synthesis of D-loop DNA and for Hstrand replication (e.g., [55]). We also found many 
possible pseudogenes. We identified them based on their $>40$ bp lengths and $>50 \%$ sequence similarity to their corresponding functional paralogs.

We also amplified and sequenced $1-5$ of seven nuclear genes (bdnf, histone $-3 a$, pomc, rag1, rho, slc8a1, and slc8a3) from each of the four afrobatrachians and five natatanurans. The PCR strategy and primers used for these genes were basically the same as in Irisarri et al. [38], but we made a primer set for slc8a3 (NCX3_FowN: GARGTCATAACWTCACARGARCG; NCX3_RevN: AAGATATCATCATCRATAATYCC) and a reverse primer for histon-3a (H3NR_mod: ATRTC CTTRGGCATRATTGTKAC). The newly determined mt (AB777216- AB777219) and nuclear (AB777220AB777233) sequences were deposited in the DDBJ/ EMBL/NCBI DNA databases.

\section{Preparation of sequence datasets for evolutionary analyses}

To perform phylogenetic and dating analyses, we used our whole-mitogenomic dataset and the sequences of nine nuclear protein-coding genes (bdnf, cxcr4, histon-3a, pomc, rag1, rag2, rho, slc8a1, and slc8a3). The taxonsampling strategy basically followed that of the recent comprehensive anuran mitogenomic study by Irisarri et al. [38], but several ranoid taxa with rearranged mt genomes (e.g., Buergeria, Babina, and Hoplobatrachus) were added to analyze the mode of evolution of the duplicated and rearranged $\mathrm{mt}$ genes. Because our phylogenetic analyses focused mainly on the family level, and to maximize the completeness of our nuclear gene data, sequences from congeneric species were merged (see Additional file 1) to form a few operational taxonomic units (OTUs) in a similar way to some previous studies (e.g., [38,56-58]). We used 36 and 45 OTUs for phylogenetic and time tree reconstructions, respectively. The 36-OTU dataset comprised only frogs, with Ascaphus and Leiopelma, which occupy the most basal positions among extant anurans (e.g., [58]), used as outgroups. The 45-OTU dataset also included nine non-frog taxa, i.e., three salamanders, three caecilians, a lizard, a bird, and a mammal, to allow more time calibration points. The details of the taxa and genes used in this study are shown in Additional file 1. Sequence data used in this study are available in Additional file 2.

Mitochondrial and nuclear gene sequences of the 45 OTUs were aligned. For each protein-coding gene, the deduced amino acids were aligned using MAFFT [59] implemented in TranslatorX [60] with the L-INS-i option and default settings. Ambiguously-aligned sites were removed using Gblocks v.0.19b [61] (also implemented in TranslatorX) with default settings. Finally, trimmed protein alignments were used to guide a codon-based alignment of nucleotide sequences. Sequences of mt rrns were aligned using MAFFT with the Q-INS-i option, in which secondary structure information was considered [62]. The mt trns were aligned manually based on their putative secondary structures. Ambiguously-aligned positions in both mt trn and $r r n$ gene alignments were excluded using Gblocks as described above. The resultant alignments for each gene were used to compare substitution rates and nucleotide compositions among rearranged and non-rearranged genes $(12 S$ and $16 S$ rrns, $n d 2$, and $n d 5$; see below). The individual nucleotide alignments were concatenated into a single dataset (the Nuc-dataset; 15,233 nucleotide sites in total) and the individual amino acid alignments of the $\mathrm{mt}$ and nuclear protein-coding genes were concatenated with the rrn $(1,921 \mathrm{bp})$ and trn sequences $(1,424 \mathrm{bp})$ into one data matrix (the AA-dataset; 5,944 amino acid and 3,345 nucleotide sites). Previous studies have suggested that long-branch attraction may mislead phylogenetic reconstructions of anuran trees because of the high evolutionary rates of neobatrachian genes (e.g., [63,64]). To minimize such artifacts, third codon positions in the nucleotide dataset were a priori excluded from the phylogenetic reconstruction and dating analyses.

The best partitioning schemes for Nuc- and AAdatasets were estimated under the Akaike information criterion (AIC) [65] using PartitionFinder v1.0.1 and PartitionFinderProtein v1.0.1, respectively [66]. For the Nuc-dataset, a seven-partition scheme was optimal: (1) first codon positions of all mt protein genes, (2) second codon positions of all $\mathrm{mt}$ proteins, (3) first codon positions of all nuclear protein genes, (4) second codon positions of all nuclear proteins, (5) $12 \mathrm{~S} \mathrm{rrn}$, (6) $16 \mathrm{~S} \mathrm{rrn}$, and (7) trns. For the AA-dataset, a scheme with 19 partitions was suggested: eight $\mathrm{mt}$ protein sequence partitions $(5$ single $\mathrm{mt}$ protein partitions and atp6/cytb/nd1/nd4L, co2/co3, and $n d 2 / n d 4$ partitions), eight nuclear protein partitions (7 single protein partitions and $c x c r 4 /$ rag1 partition), plus three mt $r r n$ partitions (= partitions 5,6 , and 7 above).

Heterogeneity in nucleotide composition among lineages negatively affects the accuracy of phylogenetic inference (e.g., [37,67]). To avoid this effect, we checked the nucleotide composition homogeneity of all seven Nuc-dataset partitions using Pearson's chi-squared $\left(\chi^{2}\right)$ test implemented in phylogears ver. 2-2.0 [68]. Although homogeneity was not rejected $(P>0.05)$ in six of seven partitions, it was rejected for the partition of the $\mathrm{mt}$ first codon positions $\left(P=1 \times 10^{-26}\right)$. For this partition, we applied the AC-coding (=RY-coding) method $[67,69,70]$ to eliminate the nucleotide composition bias ( $P=0.99$ after AC-coding). The AC-coded partition was used for phylogenetic tree reconstruction but not in the dating analysis.

Nuc- and AA-datasets and detailed information on gene partitions and substitution models are available in Additional file 3 . 


\section{Phylogenetic analyses}

Both the Nuc and AA anuran datasets (36 OTUs) were analyzed by maximum likelihood (ML) using RAxML v.7.0.3 [71] and by Bayesian inference (BI) using MrBayes5D [72], a modified version of MrBayes 3.1 [73]. The best substitution models for the nucleotide and amino-acid partitions were estimated using Kakusan4 and Aminosan, respectively [74]. To select the substitution models, we used the AIC for ML analyses and the Bayesian information criterion (BIC) for BI analyses.

The rapid hill-climbing algorithm [75] starting from 100 randomized maximum-parsimony trees was used for ML searches in RAxML, which independently optimized all substitution model parameters in all partitions. For BI, we ran 20 million generations of four simultaneous Markov chains and sampled every 1000 generations. Convergence was checked a posteriori using Tracer v.1.5 [76]. The first $10 \%$ of generations were discarded as burn-in to prevent sampling before the Markov chains reached stationarity. Support for internal branches was evaluated using bootstrap percentages (BP) from 1000 non-parametric replicates for ML and using posterior probabilities (BPP) for BI.

\section{Molecular dating analysis}

To estimate divergence times of afrobatrachians and other anurans, we used MCMCTree as implemented in PAML 4.6 [77]. This program implements a Bayesian dating method, with a soft-bound approach for age constraints and Cauchy distribution for lower-bound constraints. For this analysis, we used the full Nuc-dataset (46 OTUs) with seven data partitions (see above) and the tree topology from our phylogenetic analysis (Figure 2). The dataset and other setting files used are available in Additional file 4. Independent GTR $+\Gamma$ models were applied to each of the partitions. We applied seven calibration points suggested from fossil records as priors for divergence time estimations (lower bounds) according to Irissari et al. [38] as follows: 1) > 312 million years ago (Ma) for the Sauropsida-Synapsida split, 2) $>260 \mathrm{Ma}$ for the Archosauromorpha-Lepidosauromorpha split, 3) > $146 \mathrm{Ma}$ for the Cryptobranchidae-Hynobiidae split, 4) > $249 \mathrm{Ma}$ for the Anura-Caudata split, 5) >161 Ma for branching of Discoglossoidea, 6) > 146 Ma for branching of Pipoidea, and 7) >53 Ma for the CalyptocephalellaLechriodus split. Cauchy distributions were used with default parameters $(\mathrm{p}=0.1, \mathrm{c}=1)$. The Markov chain was run for 11 million generations with sampling every 100 generations, the first 1 million of which were discarded as burn-in. Chain convergence and adequate effective sample sizes (> 200) of all parameters were checked with Tracer [76].

The MCMCTree implemented two different molecular clock models (independent and correlated). To test which model was most suitable for our data, we performed a cross-validation analysis of the standard errors (SEs) of the posterior ages of the seven calibration nodes. Briefly, we ran the program as described above but eliminated one of the seven calibration points; the posterior SE of that node was calculated under both the independent and correlated clock models. The SE calculations were repeated for all calibration points. The sums of the SEs of all calibration points were compared between the two models. The total SE from the correlated clock model (0.00434) was smaller than that of the independent clock model (0.00449), so we adopted the former for our data.

\section{Relative-rate tests}

To compare substitution rates of $\mathrm{mt}$ genes among neobatrachian lineages, relative-rate tests (RRTs [78]) were performed using the program RRTree [79]. This program extends the method of $\mathrm{Li}$ and Bousquet [80] and compares mean rates between lineages relative to the outgroups while accounting for phylogenetic relationships using topological weighting [81]. Nucleotide genetic distances were estimated with the Kimura twoparameter substitution model [82]. We compared substitution rates of all $\mathrm{mt}$ genes, all $\mathrm{mt}$ protein-coding genes, and/or rearranged or duplicated genes ( $n d 2, n d 5,12 S$, and $16 S$ rrns) among several distinct lineages. Those lineages and the outgroup used for each comparison are shown in Tables of RRTs.

\section{Detecting changes in selective pressure on $\mathrm{mt}$ protein- coding genes in neobatrachians}

Several studies of various lineages have shown that nonsynonymous/synonymous substitution ratios $(\mathrm{dN} / \mathrm{dS}$ ratio $=\omega$ ) can successfully be used to identify changes in selective pressure, including in highly-divergent taxa $[38,83,84])$. We compared many so-called "branch" models [see 83] with different assumptions about selection coefficient ratios to determine in which frog lineages changes in selective pressure on the mt proteincoding genes had occurred and to understand whether accelerated evolutionary rates (especially for duplicated and rearranged genes) in neobatrachians were due to changes in selective pressure. The codeml program implemented PAML 4.6 [77] was used to estimate the likelihood of the tree (having the Figure 2 topology but including only 22 neobatrachian taxa) and the $\omega$ values of the branches under the given models for the dataset of all $\mathrm{mt}$ protein-coding genes and for single-gene alignments of $n d 2$ and $n d 5$, which are duplicated or rearranged in some neobatrachian lineages. Branch lengths were first optimized for each dataset assuming a single $\omega$ for the whole tree, and they were fixed while the other parameters were estimated. The null model had a single $\omega$ value for all branches, while the alternative models allowed unique $\omega$ values on one or more 
designated branches. The alternative models were compared against the null model using the likelihood ratio test (LRT), and all models were compared simultaneously using the AIC [65].

\section{Results and discussion}

Phylogeny of anurans and divergence ages of afrobatrachians

We first reconstructed a phylogenetic tree for anurans. Figure 2 shows the ML tree $(-\ln L=134944.28)$ derived from the Nuc-dataset. The BI tree generated from the same dataset and the ML and $\mathrm{BI}$ trees from the AAdataset recovered the same topology, so we assumed that this was the best phylogenetic hypothesis and used it in subsequent dating and other evolutionary analyses.

Our phylogenetic hypothesis was basically congruent with those of recent phylogenetic studies (e.g., [38,40, 51,52]) and confirmed the following relationships for higher anuran taxa. (i) Neobatrachia is monophyletic. (ii) "Archaeobatrachia" is paraphyletic with respect to Neobatrachia. (iii) Heleophryne is most basal among neobatrachians. (ix) Ranoides and Hyloides (sensu Frost et al. [40]; excluding family Sooglossidae) are both monophyletic within Neobatrachia. (v) The three major clades of Ranoides are Afrobatrachia, Microhylidae, and Natatanura. All of our trees recovered a sister relationship between Ranoides and Sooglossidae (BPPs $=99 / 94 \%$ in Nuc/AA-datasets, respectively), but with low BP supports as in many previous studies $[38,51]$.

Although many alternative hypotheses for the afrobatrachian families exist (see [41]), afrobatrachian monophyly has been suggested by several recent comprehensive studies (e.g., [41,51,52]). Likewise, our results strongly supported afrobatrachian monophyly (BP $=100 / 98 \%$, $\mathrm{BPP}=100 / 100 \%$ in the Nuc/AA-datasets, respectively). We also discovered a synapomorphic mitogenomic structure (a rearranged "WNACY" trn cluster shared by all four afrobatrachian families; Figure 1 and see below), although no morphological synapomorphy for afrobatrachians has yet been found [41].

The phylogenetic relationships of the three major ranoid groups (Afrobatrachia, Microhylidae, and Natatanura) have been very problematic. Morphological studies suggested a close affinity of Afrobatrachia and Natatanura [85-87]. In contrast, rag1 data indicated a sister relationship between Natatanura and Microhylidae [50]. Although recent molecular studies have tended to prefer an Afrobatrachia + Microhylidae grouping [51,52,88], statistical support for this clade was generally low. Furthermore, our recent analyses recovered both the Afrobatrachia + Microhylidae and Afrobatrachia + Natatanura clades, depending on the dataset used [89]. The data used here, the longest molecular datasets so far applied to afrobatrachian phylogeny, support the Afrobatrachia + Microhylidae hypothesis. Although BP support for this node from the AA-dataset was rather low (61\%), the Nuc-dataset gave a relatively high BP $(76 \%)$, and the Nuc- and AAdatasets had 100 and $99 \%$ BPPs, respectively.

A time tree of anurans was reconstructed using the best tree topology and the Nuc-dataset (excluding the AC-coded partition of the mt 1st codons). The resultant ages of major anuran groups are shown in Figure 2 (nodes I-XVI). The divergence time between Afrobatrachia and Microhylidae (VI) was estimated as $100 \mathrm{Ma}$ with a $95 \%$ confidence interval (CI) of 82-119 Ma, while the last common ancestor of the extant afrobatrachians existed $91 \mathrm{Ma}$ (CI, 74-109 Ma). These ages were slightly younger than in previous studies, although the previously suggested ages (117-143 Ma and 102-107 Ma, respectively [38,51,89-92]) were within the $95 \%$ CI ranges. The estimated split of Afrobatrachia from other ranoids (Microhylidae) at $100 \mathrm{Ma}$ corresponds to the continental separation of Africa and South Africa (e.g., [93]), the last stage of the break-up of the Gondwana supercontinent, which may explain why the distribution of afrobatrachians is limited to Africa.

\section{Extensively rearranged $\mathrm{mt}$ genomes in afrobatrachians}

In this study, we sequenced the whole mt genomes of four afrobatrachians representing all afrobatrachian families as follows: Breviceps adspersus (Brevicipitidae; genome size = 28,757 bp), Hemisus marmoratus (Hemisotidae; 20,093 bp), Hyperolius marmoratus (Hyperoliidae; 22,595 bp), and Trichobatrachus robustus (Arthroleptidae; 21,418 bp). The mitogenomic organizations of these afrobatrachians and other anurans are shown in Figure 1. Almost all basal anurans (= archaeobatrachians, excluding Leiopelma with $n d 6$ and $\operatorname{trn} \mathrm{P}$ translocations [43]) have the vertebrate-type $\mathrm{mt}$ gene arrangement. A slight rearrangement of this order, with translocations of three trns yielding the LTPF trn cluster, is shared by most neobatrachians (neobatrachian-type arrangement). This gene arrangement was likely present in the common ancestor of neobatrachians [38]. Within neobatrachians, extensive gene rearrangements, with duplications and/or rearrangements of $n d 5$, trns, and CR, have been reported in three distinct natatanuran lineages: the families Rhacophoridae + Mantellidae (= Rhacophoroidea; Figure 2 and see [4]), a part of Ranidae [47,49], and a part of Dicroglossidae (e.g., [48]). We also discovered extensively-rearranged $\mathrm{mt}$ genomes in afrobatrachians.

Among the afrobatrachians analyzed, the gene order of the Hemisus mt genome was very similar to the neobatrachian-type arrangement, except that $\operatorname{trn} \mathrm{P}$ in the typical LTPF trn cluster was translocated (PLTF in Hemisus) and $\operatorname{trn} \mathrm{N}-\mathrm{O}_{\mathrm{L}}$ and $\operatorname{trn} \mathrm{A}$ in the typical $\mathrm{WAN}-\mathrm{O}_{\mathrm{L}}-$ CY trn cluster were exchanged (WN-O $-\mathrm{L}-\mathrm{ACY}$ in Hemisus) (Figure 1). In contrast, the other three afrobatrachians showed extensive $\mathrm{mt}$ gene rearrangements. Their $\mathrm{mt}$ 
genomes were characterized by many duplicated genes and CRs and by pseudogenes (remnants of duplicated genes). Mainly because of these duplicated segments, the afrobatrachian mt genomes were larger than those of other vertebrates (generally 16-17 kbp (e.g., [1])). In particular, Breviceps has the largest known vertebrate $\mathrm{mt}$ genome; the second largest being $25,972 \mathrm{bp}$, with a 9 kbp duplication including $C R+12 S$ and $16 S$ rrns, in a parthenogenetic strain of the gecko Heteronotia binoei [94].

In the Breviceps $\mathrm{mt}$ genome, the region consisting of LTPF trns-12S rrn-trnV-16S rrn was tandemly triplicated. The trn $\mathrm{HS}_{2}$ segment was translocated from its original position (between $n d 4$ and $n d 5$ ) into the triplicated region (between copies 2 and 3; Figure 1). Furthermore, the $\operatorname{trn} \mathrm{WN}-\mathrm{O}_{\mathrm{L}}$ segment was duplicated, and an additional CR occurred between these two copies. Many of the duplicate genes became pseudogenes (one pseudo- $12 S$ rrn, two pseudo- $16 S$ rrns, one pseudo-trnF, two pseudo-trnP, two pseudo-trn $\mathrm{Vs}$, and one pseudo$\operatorname{trn} \mathrm{T}$ ) or were deleted from the genome (possibly two $t_{r n} \mathrm{~L}_{2} \mathrm{~S}$ and one trn T). However, both copies of $12 \mathrm{~S} \mathrm{rrn}$ and trnF appear to have retained their functions, because each copy has the same or quite similar nucleotide sequences $(99.3 \%$ similarity for the $12 S \mathrm{rrns} ; 100 \%$ for the trnFs).

In the Hyperolius mt genome, the typical LTPF trn cluster was rearranged to $\mathrm{PTL}_{2} \mathrm{~F}$, and relatively large noncoding regions were found between $\operatorname{trn} \mathrm{P}$ and $\operatorname{trn} \mathrm{T}$ $(1.3 \mathrm{kbp})$ and between $\operatorname{trn} \mathrm{L}_{2}$ and $\operatorname{trn} \mathrm{F}(0.4 \mathrm{kbp})$. Furthermore, the trnM-nd2 segment was duplicated, with an additional CR inserted between the two copies. One copy of each gene was converted into a pseudogene (Figure 1). Similarly, in the Trichobatrachus mt genome, the $t r n \mathrm{HS}_{2}-n d 5$ segment was duplicated, with an additional CR-LTPF trns segment occurring between the copies and conversion of duplicated genes to pseudogenes (Figure 1).

The duplicated genes and rearrangement patterns differed among the afrobatrachian taxa. Thus, these extensive mitogenomic reorganizations clearly occurred independently in at least three distinct afrobatrachian lineages (i.e., breviciptids, hyperoliids, and arthroleptids; Figure 2). However, the WN-O $\mathrm{L}-\mathrm{ACY}$ trn cluster, modified from the typical neobatrachian arrangement, was shared by all four afrobatrachian families and has not been found in any other vertebrate $\mathrm{mt}$ genome ([28], see also the Mitozoa database [95]). This gene order can only be explained by a complex rearrangement process (at least two duplication events, or one duplication and one insertion event; Additional file 5). Thus, the data strongly suggested that this arrangement occurred in the common ancestral lineage of afrobatrachians and can be regarded as a novel molecular synapomorphy for this taxon.

\section{Mechanisms of gene rearrangement and concerted evolution in afrobatrachian $\mathrm{mt}$ genomes Mechanism of $\mathrm{mt}$ gene rearrangements}

Mitochondrial genomes of bilateral animals (including vertebrates) generally contain only one set of genes, a single CR, and no introns or long intergenic spacers (e.g., $[1,2])$. In such genomes, unregulated gene rearrangement would destroy an essential single-copy gene. Thus, rearrangements in animal $\mathrm{mt}$ genomes are generally explained by the "duplication and deletion model" (e.g., $[16,28]$ ): first, a multi-gene (and CR) portion of the genome is duplicated, and then one duplicate gene copy becomes nonfunctional (a pseudogene) and is subsequently excised from the genome. The afrobatrachian $\mathrm{mt}$ genomes analyzed here had many duplicated genes, CRs, and pseudogenes, clearly indicating the occurrence of duplication-and-deletion type genomic rearrangements.

Duplications in animal mt genomes are hypothesized to mainly occur by replication errors, such as slippedstrand mispairing or asynchrony in the points of initiation and termination (e.g., [26,28]). Such replication errors only generate tandem duplications [26]; thus, the TDRL model can explain the tandemly-duplicated gene segments in afrobatrachian $\mathrm{mt}$ genomes. However, several non-tandemly duplicated genes and CRs in the afrobatrachian mt genomes (Figure 1) cannot be easily explained by this model. In particular, an additional copy of non-tandemly duplicated segments was sometimes positioned between other tandemly-copied segments. For example, in the Breviceps mt genome, an additional copy of the trn $\mathrm{HS}_{2}$ segments occurred between the tandemly triplicated LTPF trns-12S rrn-trnV-16S rrn segments. Also, additional CRs occurred in the Breviceps and Hyperolius mt genomes between the tandemlyduplicated $t r n \mathrm{WN}-\mathrm{O}_{\mathrm{L}}$ and $t r n \mathrm{M}-n d 2$ segments, respectively. Finally, in the Trichobatrachus $\mathrm{mt}$ genome, an additional CR-LTPF trns segment existed between tandemly-duplicated trn $\mathrm{HS}_{2}-n d 5$ segments.

Previously, we proposed a model (the first tandem and second non-tandem duplication model) to explain nontandem duplications in animal mt genomes [4]. In this model, a tandem duplication initially introduces redundant genes or CRs into a mt genome (one copy is nonessential and can be destroyed), then a non-tandem duplication (via several recombination related processes; see [4]) makes additional gene and CR copies somewhere in the tandemly-copied regions. The non-tandem copies located within tandemly-copied regions in the afrobatrachian genomes demonstrate the validity of this model.

\section{Mechanism of concerted evolution}

Duplications of CRs are often observed in animal mt genomes, and in most cases the copied CRs are highly 
similar to one another (e.g., [4,27,96]). Likewise, the copied CRs in afrobatrachian mt genomes had very similar sequences $[99.0 \%$ across 3,148 comparable bp in Breviceps, $99.6 \% / 1,857$ bp in Hyperolius, and 99.7\%/ 1,390 bp in Trichobatrachus]. The strong nucleotide similarities of these multiple CRs may be maintained by sequence homogenization mechanisms, i.e., concerted evolution ([27]; also see below). In addition to the CRs, two trnPF-12S rrn-trnV-16S rrn segments (copies 1 and 3 , Figure 1) seem to have experienced homogenization in the Breviceps mt genome. These non-neighboring copies of the tandemly triplicated segments have very high nucleotide similarity $(98.5 \% / 1,197 \mathrm{bp})$. In contrast, their neighboring regions were quite divergent $(65 \% / 1,148 \mathrm{bp}$ between copies 1 and 2; 65\%/1,134 bp between copies 2 and 3).

Two distinct concerted evolution mechanisms have been suggested: (1) homologous recombination and (2) illicit DNA replication accompanied by nascent strand slippage and a loop out of an extra-copied region [27]. Homologous recombination seems to cause the concerted evolution in afrobatrachian $\mathrm{mt}$ genomes (at least in copies 1 and 3 of the triplicated segments in Breviceps), because the illicit replication process cannot easily homogenize non-neighboring copies [4,29].

\section{Substitution rates and changes in selective pressure}

Nucleotide substitution in neobatrachian mt genomes occurs more rapidly than in archaeobatrachians (e.g., [63]). Irisarri et al. [38] concluded that the accelerated substitution rates in protein-coding genes were caused by a relaxation of purifying selection in the ancestral lineage of neobatrachians. To check the occurrences of further changes in substitution rates and selective pressures within neobatrachians, we first compared the substitution rates of $\mathrm{mt}$ genes within five alignment categories (all $\mathrm{mt}$ genes, all $\mathrm{mt}$ protein-coding genes, $12 \mathrm{~S}$ rrn, $16 \mathrm{~S} \mathrm{rrn}$, and all trns) of four neobatrachian lineages (non-ranoid neobatrachians and three major ranoid lineages: Afrobatrachia, Natatanura, and Microhylidae; Table 1) using the relative rate test. First, we compared the mt genes of ranoids and non-ranoids. The substitution rates of most ranoid $\mathrm{mt}$ genes (excluding trns) were significantly faster than those of non-ranoids (Nos. 1-5 in Table 1: $P \leq$ $1 \times 10^{-7}$ in all $\mathrm{mt}$ genes and all $\mathrm{mt}$ protein-coding genes [No. 1, 2]; $P=0.014$ and 0.049 in 12 Srrn and 16Srrn [No. 3, 4]; $P=0.518$ in trns [No. 5]), in congruence with a previous study [38]. Separate comparisons showed that there was no significant substitution rate heterogeneity among the microhylid and non-ranoid neobatrachian mt genes (Nos. 6-9, $P>0.05$ ), with the exception of trns (No. 10, $P=$ 0.005 ), yet almost all $\mathrm{mt}$ genes of natatanurans and afrobatrachians had significantly faster substitution rates than those of non-ranoids (Nos. $11-20, P=0.008$ to $P \leq$
$1 \times 10^{-7}$, excluding $16 \mathrm{~S} r r n$ [No. $14, P=0.119$ ] and trns [No. $15, P=0.256$ ] of natatanurans).

Among three major ranoid lineages, the substitution rates of all afrobatrachian $\mathrm{mt}$ genes were faster than those of microhylids (Nos. 21-25, $P=0.014$ to $P \leq 1 \times 10^{-7}$; Table 1). Similarly, the substitution rates of natatanurans tended to be faster than those of microhylids (Nos. 26-30, $P=1 \times 10^{-5}$ to $P \leq 1 \times 10^{-7}$ excluding $12 \mathrm{~S}$ and $16 \mathrm{~S} \mathrm{rrns}$ [Nos. 28 and 29, $P=0.019$ and 0.211, respectively]. For Nos. $21-35$, we used 0.0167 [ $=0.005 / 3]$ as the significance level due to multiple testing; see [79] and Table 1). The substitution rate of all natatanuran protein-coding genes was significantly faster than that of afrobatrachians (No. 32 ), although other mt genes had no significant differences in substitution rates between these taxa (Nos. 31, 33-35). Overall, the relative substitution rates of the neobatrachian mt genes can be summarized as Natatanurans $\geq$ Afrobatrachians $>$ Microhylidae $\approx$ non-ranoid neobatrachians.

To check whether the substitution rate differences of the mt protein-coding genes were caused by relaxed selective pressure and also to specify in which lineages the selective pressure had changed, we compared 19 branch models having distinct $\mathrm{dN} / \mathrm{dS}$ ratios $(\omega)$ on designated branches of the best neobatrachian topology (Table 2). All 19 models produced significantly higher tree $\ln L$ values compared to the null model having a single $\omega$ for all branches $(\omega=0.0543, \quad-\ln L=150123.54, \quad$ AIC $=$ 300333.08). The best model, with the highest $\ln L$ and the lowest AIC $(-\ln L=150076.11$ and AIC $=300246.22$ : No. 15 in Table 2), had four distinct $\omega$ values and one background $\omega$ (0.054). According to this model, the mt protein genes are under strong purifying selection $(\omega>0)$ in all anuran lineages. Selection was relaxed in three ancestral lineages of (1) Ranoides ( $\omega=0.093)$, (2) Afrobatrachia $(\omega=$ $0.107)$, and (3) Natatanura $(\omega=0.090)$, yet the selection increased in all microhylid lineages (0.042). The pattern of selective pressure changes in different linages agreed rather well with the substitution rate trends among neobatrachians (Natatanurans $\geq$ Afrobatrachians $>\mathrm{Mi}$ crohylidae $\approx$ non-ranoid neobatrachians), suggesting that relaxed purifying selection was a cause of substitution rate acceleration in neobatrachian $\mathrm{mt}$ genomes.

The tendency of highly rearranged mt genomes to have high nucleotide substitution rates has been observed in some animal taxa (e.g., mollusks [96-98]; ascidians [99]; lampshells [100]), and a positive correlation between substitution rate and genomic rearrangement has been demonstrated in arthropods [101,102]. Shao et al. [101] proposed that accelerated nucleotide changes lead to many illicit substitutions at the initiation and termination points of $\mathrm{mt}$ genome replication; such illicit initiation and termination points cause frequent tandem duplications, resulting in frequent gene rearrangements. In accordance with previous studies, 


\section{Table 1 Substitution rate comparisons of neobatrachian mitochondrial genes}

\begin{tabular}{|c|c|c|c|c|c|c|c|c|}
\hline No & Compared genes & Outgroups & Compared lineage 1 & Compared lineage 2 & Substitutio & rate & Probability & Significance \\
\hline & & & & & Lineage 1 & Lineage 2 & & \\
\hline $\begin{array}{l}\text { Ranoides vs. } \\
\text { non-ranoides }\end{array}$ & & & & & & & & $* P<0.05$ \\
\hline 1 & All mt genes & Archaeobatrachians & Non-ranoid neobatrachians & All ranoides & 0.3712 & 0.3934 & $\leq 1.00 \times 10^{-7}$ & * \\
\hline 2 & All protein-coding genes & Archaeobatrachians & Non-ranoid neobatrachians & All ranoides & 0.4190 & 0.4440 & $\leq 1.00 \times 10^{-7}$ & * \\
\hline 3 & $125 \mathrm{rrn}$ & Archaeobatrachians & Non-ranoid neobatrachians & All ranoides & 0.2121 & 0.2406 & 0.0141 & * \\
\hline 4 & $165 \mathrm{rrn}$ & Archaeobatrachians & Non-ranoid neobatrachians & All ranoides & 0.2076 & 0.2232 & 0.0485 & * \\
\hline 5 & $\begin{array}{l}\text { All } \\
\text { trns }\end{array}$ & Archaeobatrachians & Non-ranoid neobatrachians & All ranoides & 0.2786 & 0.2848 & 0.5180 & \\
\hline $\begin{array}{l}\text { Three major ranoid } \\
\text { groups vs. non- } \\
\text { ranoides (separate } \\
\text { comparisons) }\end{array}$ & & & & & & & & $* P<0.05$ \\
\hline 6 & All mt genes & Archaeobatrachians & Non-ranoid neobatrachians & Microhylids & 0.3712 & 0.3656 & 0.2006 & \\
\hline 7 & All protein-coding genes & Archaeobatrachians & Non-ranoid neobatrachians & Microhylids & 0.4190 & 0.4147 & 0.4263 & \\
\hline 8 & $125 \mathrm{rrn}$ & Archaeobatrachians & Non-ranoid neobatrachians & Microhylids & 0.2121 & 0.2188 & 0.6312 & \\
\hline 9 & $165 \mathrm{rrn}$ & Archaeobatrachians & Non-ranoid neobatrachians & Microhylids & 0.2076 & 0.2110 & 0.7253 & \\
\hline 10 & All trns & Archaeobatrachians & Non-ranoid neobatrachians & Microhylids & 0.2786 & 0.2451 & 0.0053 & * \\
\hline 11 & All mt genes & Archaeobatrachians & Non-ranoid neobatrachians & Natatanurans & 0.3712 & 0.4051 & $\leq 1.00 \times 10^{-7}$ & $*$ \\
\hline 12 & All protein-coding genes & Archaeobatrachians & Non-ranoid neobatrachians & Natatanurans & 0.4190 & 0.4592 & $\leq 1.00 \times 10^{-7}$ & * \\
\hline 13 & $125 \mathrm{rrn}$ & Archaeobatrachians & Non-ranoid neobatrachians & Natatanurans & 0.2121 & 0.2469 & 0.0084 & * \\
\hline 14 & $165 \mathrm{rrn}$ & Archaeobatrachians & Non-ranoid neobatrachians & Natatanurans & 0.2076 & 0.2214 & 0.1198 & \\
\hline 15 & All trns & Archaeobatrachians & Non-ranoid neobatrachians & Natatanurans & 0.2786 & 0.2911 & 0.2562 & \\
\hline 16 & All mt genes & Archaeobatrachians & Non-ranoid neobatrachians & Afrobatrachians & 0.3712 & 0.3977 & $\leq 1.00 \times 10^{-7}$ & * \\
\hline 17 & All protein-coding genes & Archaeobatrachians & Non-ranoid neobatrachians & Afrobatrachians & 0.4190 & 0.4429 & $4.00 \times 10^{-7}$ & * \\
\hline 18 & $125 \mathrm{rrn}$ & Archaeobatrachians & Non-ranoid neobatrachians & Afrobatrachians & 0.2121 & 0.2499 & 0.0046 & * \\
\hline 19 & $165 \mathrm{rrn}$ & Archaeobatrachians & Non-ranoid neobatrachians & Afrobatrachians & 0.2076 & 0.2389 & $5.46 \times 10^{-5}$ & * \\
\hline 20 & All trns & Archaeobatrachians & Non-ranoid neobatrachians & Afrobatrachians & 0.2786 & 0.3119 & 0.0032 & * \\
\hline $\begin{array}{l}\text { Comparisons among } \\
\text { three major ranoid } \\
\text { lineages }\end{array}$ & & & & & & & & ${ }^{*} P<0.0167$ \\
\hline 21 & All mt genes & Archaeobatrachians & Afrobatrachians & Microhylids & 0.3977 & 0.3656 & $\leq 1.00 \times 10^{-7}$ & * \\
\hline 22 & All protein-coding genes & Archaeobatrachians & Afrobatrachians & Microhylids & 0.4429 & 0.4147 & $\leq 1.00 \times 10^{-7}$ & * \\
\hline 23 & $125 \mathrm{rrn}$ & Archaeobatrachians & Afrobatrachians & Microhylids & 0.2499 & 0.2188 & 0.0147 & * \\
\hline
\end{tabular}

All protein-coding genes
Archaeobatrachians

Afrobatrachians
0.4429 0.2188 
Table 1 Substitution rate comparisons of neobatrachian mitochondrial genes (Continued)

\begin{tabular}{|c|c|c|c|c|c|c|c|c|}
\hline 24 & $165 \mathrm{rrn}$ & Archaeobatrachians & Afrobatrachians & Microhylids & 0.2389 & 0.2110 & $1.89 \times 10^{-3}$ & * \\
\hline 25 & All trns & Archaeobatrachians & Afrobatrachians & Microhylids & 0.3119 & 0.2451 & $\leq 1.00 \times 10^{-7}$ & * \\
\hline 26 & All mt genes & Archaeobatrachians & Natatanurans & Microhylids & 0.4051 & 0.3656 & $\leq 1.00 \times 10^{-7}$ & * \\
\hline 27 & All protein-coding genes & Archaeobatrachians & Natatanurans & Microhylids & 0.4592 & 0.4147 & $\leq 1.00 \times 10^{-7}$ & * \\
\hline 28 & $125 \mathrm{rrn}$ & Archaeobatrachians & Natatanurans & Microhylids & 0.2469 & 0.2188 & 0.0192 & \\
\hline 29 & $165 \mathrm{rrn}$ & Archaeobatrachians & Natatanurans & Microhylids & 0.2214 & 0.2110 & 0.2260 & \\
\hline 30 & All trns & Archaeobatrachians & Natatanurans & Microhylids & 0.2911 & 0.2451 & $3.00 \times 10^{-5}$ & $*$ \\
\hline 31 & All mt genes & Archaeobatrachians & Natatanurans & Afrobatrachians & 0.4051 & 0.3977 & 0.0275 & \\
\hline 32 & All protein-coding genes & Archaeobatrachians & Natatanurans & Afrobatrachians & 0.4592 & 0.4429 & $5.44 \times 10^{-5}$ & * \\
\hline 33 & $125 \mathrm{rrn}$ & Archaeobatrachians & Natatanurans & Afrobatrachians & 0.2469 & 0.2499 & 0.7990 & \\
\hline 34 & $165 \mathrm{rrn}$ & Archaeobatrachians & Natatanurans & Afrobatrachians & 0.2214 & 0.2389 & 0.0233 & \\
\hline 35 & All trns & Archaeobatrachians & Natatanurans & Afrobatrachians & 0.2911 & 0.3119 & 0.0525 & \\
\hline
\end{tabular}


Table 2 Comparison of branch models and branch specific changes in the selection coefficient ( $\omega$ ) among neobatrachian mitochondrial protein-coding genes

\begin{tabular}{|c|c|c|c|c|c|c|c|c|c|c|c|c|}
\hline \multirow[t]{3}{*}{ No of models } & \multirow[t]{3}{*}{ Background $\omega$} & \multicolumn{8}{|c|}{ Models (designated branches having distinct $\omega$ ) and estimated $\omega$} & \multirow[t]{3}{*}{$-\ln L$} & \multirow{3}{*}{$\begin{array}{l}P \text { of Likelihood ratio } \\
\text { test (vs. null model) }\end{array}$} & \multirow[t]{3}{*}{ AIC } \\
\hline & & \multicolumn{2}{|l|}{ Ranoides } & \multicolumn{2}{|c|}{ Natatanura } & \multicolumn{2}{|c|}{ Afrobatrachia } & \multicolumn{2}{|c|}{ Microhylidae } & & & \\
\hline & & Ancestral branch & All branches & Ancestor & All & Ancestor & All & Ancestor & All & & & \\
\hline Null & 0.0543 & (single $\omega$ for all ne & obatrachian branches) & & & & & & & 150123.5378 & - & 300333.08 \\
\hline 1 & 0.0538 & 0.0962 & - & - & - & - & - & - & - & 150106.2460 & $3.09 \times 10^{-8}$ & 300300.49 \\
\hline 2 & 0.0518 & - & 0.0555 & - & - & - & - & - & - & 150118.9262 & 0.0099 & 300325.85 \\
\hline 3 & 0.0502 & - & 0.0569 (excluding microhylids) & - & - & - & - & - & - & 150107.2616 & $8.54 \times 10^{-8}$ & 300302.52 \\
\hline 4 & 0.0515 & - & - & - & 0.0555 & - & 0.0575 & - & - & 150114.3513 & $1.02 \times 10^{-4}$ & 300318.70 \\
\hline 5 & 0.0537 & - & - & 0.0918 & - & 0.1034 & - & - & - & 150107.1658 & $7.76 \times 10^{-8}$ & 300304.33 \\
\hline 6 & 0.0530 & - & - & 0.0921 & 0.0573 & - & - & - & - & 150107.0380 & $6.83 \times 10^{-8}$ & 300304.08 \\
\hline 7 & 0.0537 & - & - & - & 0.0548 & 0.1030 & - & - & - & 150118.9788 & 0.0105 & 300327.96 \\
\hline 8 & 0.0537 & 0.0962 & - & - & - & - & - & 0.0596 & - & 150105.5203 & $1.50 \times 10^{-8}$ & 300301.04 \\
\hline 9 & 0.0546 & 0.0957 & - & - & - & - & - & - & 0.0426 & 150091.4881 & $1.21 \times 10^{-14}$ & 300272.98 \\
\hline 10 & 0.0498 & - & 0.0569 & - & - & - & - & 0.0595 & - & 150105.2662 & $1.16 \times 10^{-8}$ & 300300.53 \\
\hline 11 & 0.0517 & - & 0.0569 & - & - & - & - & - & 0.0425 & 150099.0388 & $2.29 \times 10^{-11}$ & 300288.08 \\
\hline 12 & 0.0532 & 0.0935 & - & 0.0887 & - & 0.0989 & - & 0.0572 & - & 150091.0091 & $2.50 \times 10^{-13}$ & 300276.02 \\
\hline 13 & 0.0522 & 0.0947 & - & 0.0891 & - & - & 0.0575 & 0.0586 & - & 150087.6890 & $9.94 \times 10^{-15}$ & 300269.38 \\
\hline 14 & 0.0532 & 0.0942 & - & 0.0901 & - & - & 0.0576 & - & 0.0423 & 150076.2887 & $1.46 \times 10^{-19}$ & 300246.58 \\
\hline 15 & 0.0541 & 0.0931 & - & 0.0899 & - & 0.1068 & - & - & 0.0419 & 150076.1116 & $1.22 \times 10^{-19}$ & 300246.22 \\
\hline 16 & 0.0523 & 0.0962 & - & - & 0.0554 & 0.1000 & - & 0.0582 & - & 150098.5309 & $3.59 \times 10^{-10}$ & 300291.06 \\
\hline 17 & 0.0537 & 0.0954 & - & - & 0.0554 & 0.0537 & - & - & 0.0422 & 150086.0065 & $1.93 \times 10^{-15}$ & 300266.01 \\
\hline 18 & 0.0497 & 0.0981 & - & - & 0.0554 & - & 0.0575 & 0.0598 & - & 150090.0150 & $9.53 \times 10^{-14}$ & 300274.03 \\
\hline 19 & 0.0517 & 0.0971 & - & - & 0.0554 & - & 0.0576 & - & 0.0426 & 150084.0983 & $3.01 \times 10^{-16}$ & 300262.20 \\
\hline
\end{tabular}

Background $\omega=\omega$ of non-designated branches. All protein-coding gene data of all 22 neobatrachians was used in this comparison. The best model is shown in bold. 
most large mitogenomic rearrangements in anurans were observed in natatanurans and afrobatrachians belonging to the fast-substitution lineages. However, when we performed RRT between non-rearranged (Hemisus, Limnonectes, Lithobates, and two Microhyla) and rearranged ranoids, significant substitution rate differences were not observed in any of the five alignment categories compared here $[P=0.07$ (all $\mathrm{mt}$ genes) to $P=$ $0.8(12 S \mathrm{rrn})]$. Given these results, we concluded that the fast nucleotide substitution rate increased the propensity of mitogenomic rearrangements but were not an absolute requirement.

\section{Tests of evolutionary hypotheses related to the} duplicated and rearranged genes

The evolutionary trends of duplicated and rearranged genes in animal mt genomes have not been well researched because of the relative rarity of such genomic reorganizations and the lack of information on lineages with duplication and rearrangement events. Both rearranged and non-rearranged mt genomes were observed within ranoids with relatively recent divergences $(<104 \mathrm{Ma})$, and the lineages with duplications and rearrangements were well specified in this taxon. We consequently tested two evolutionary trends expected in duplicated and rearranged genes using the ranoid mitogenomic data.

\section{Substitution rates of duplicated and rearranged $\mathrm{mt}$ genes}

During the evolution of duplicated genes, purifying selection is thought to be relaxed on one copy because of its redundant function; this relaxation should lead to an increased nucleotide substitution rate in one duplicate (e.g., [30-32]). To test this hypothesis, we compared the substitution rates of duplicated and rearranged genes, i.e., the triplicated $12 S$ and $16 S$ rrns in the Breviceps lineage, the duplicated $n d 2$ in the Hyperolius lineage, the duplicated $n d 5$ in the Trichobatrachus lineage, and the rearranged $n d 5$ within a part of Ranidae (Babina), a part of Dicroglossidae (Fejervarya and Hoplobatrachus), and Rhacophoroidea (Figure 2) to those of the non-rearranged ranoid lineages (Table 3). The duplicated and rearranged genes did not always have faster nucleotide substitution rates. In particular, there was no significant substitution rate heterogeneity between the triplicated $12 S$ and $16 S$ rrns in Breviceps and those of their non-duplicated counterparts

Table 3 Substitution rates of duplicated and rearranged mitochondrial genes compared to non-rearranged genes

\begin{tabular}{|c|c|c|c|c|c|c|c|c|}
\hline \multirow[t]{2}{*}{ No } & \multirow{2}{*}{$\begin{array}{l}\text { Compared } \\
\text { genes }\end{array}$} & \multirow[t]{2}{*}{ Outgroups } & \multirow{2}{*}{$\begin{array}{l}\text { Compared lineage } 1 \\
\text { Non-rearranged taxa }\end{array}$} & \multirow{2}{*}{$\begin{array}{l}\text { Compared lineage } 2 \\
\text { Rearranged taxa }\end{array}$} & \multicolumn{2}{|c|}{ Substitution rates } & \multirow[t]{2}{*}{ Probability } & \multirow{2}{*}{$\begin{array}{l}\text { Significance } \\
*\end{array}$} \\
\hline & & & & & Lineage 1 & Lineage 2 & & \\
\hline 1 & $125 \mathrm{rrn}$ & $\begin{array}{l}\text { Non-ranoid } \\
\text { neobatrachians }\end{array}$ & Non-Breviceps ranoids & Breviceps & 0.2364 & 0.2306 & 0.6882 & \\
\hline 2 & $165 \mathrm{rrn}$ & $\begin{array}{l}\text { Non-ranoid } \\
\text { neobatrachians }\end{array}$ & Non- Breviceps ranoids & Breviceps & 0.2187 & 0.2352 & 0.1495 & \\
\hline 3 & nd5 & $\begin{array}{l}\text { Non-ranoid } \\
\text { neobatrachians }\end{array}$ & $\begin{array}{l}\text { Ranoides without nd5 } \\
\text { rearrangement }\end{array}$ & $\begin{array}{l}\text { Part of ranids } \\
\text { (Babina) }\end{array}$ & 0.4832 & 0.5118 & 0.1025 & \\
\hline 4 & nd5 & $\begin{array}{l}\text { Non-ranoid } \\
\text { neobatrachians }\end{array}$ & $\begin{array}{l}\text { Ranoides without nd5 } \\
\text { rearrangement }\end{array}$ & Trichobatrachus & 0.4832 & 0.4303 & 0.0011 & * \\
\hline 5 & nd5 & $\begin{array}{l}\text { Non-ranoid } \\
\text { neobatrachians }\end{array}$ & $\begin{array}{l}\text { Non-Trichobatrachus } \\
\text { afrobatrachians }\end{array}$ & Trichobatrachus & 0.4668 & 0.4599 & 0.6581 & \\
\hline 6 & nd5 & $\begin{array}{l}\text { Non-ranoid } \\
\text { neobatrachians }\end{array}$ & $\begin{array}{l}\text { Ranoides without nd5 } \\
\text { rearrangement }\end{array}$ & Rhacophoroidea & 0.4832 & 0.5296 & $5.40 \times 10^{-4}$ & * \\
\hline 7 & nd5 & $\begin{array}{l}\text { Non-ranoid } \\
\text { neobatrachians }\end{array}$ & $\begin{array}{l}\text { Ranoides without } n d 5 \\
\text { rearrangement }\end{array}$ & $\begin{array}{l}\text { Part of dicroglossids } \\
\text { (Fejervarya and } \\
\text { Hoplobatrachus) }\end{array}$ & 0.4832 & 0.6403 & $\leq 1.00 \times 10^{-7}$ & * \\
\hline 8 & $n d 2$ & $\begin{array}{l}\text { Non-ranoid } \\
\text { neobatrachians }\end{array}$ & Non- Hyperolius ranoids & Hyperolius & 0.5064 & 0.6555 & $4.38 \times 10^{-7}$ & * \\
\hline 9 & All mt genes & $\begin{array}{l}\text { Non-ranoid } \\
\text { neobatrachians }\end{array}$ & $\begin{array}{l}\text { Ranoides without nd5 } \\
\text { rearrangement }\end{array}$ & Rhacophoroidea & 0.3769 & 0.3874 & 0.0024 & * \\
\hline 10 & All mt genes & $\begin{array}{l}\text { Non-ranoid } \\
\text { neobatrachians }\end{array}$ & $\begin{array}{l}\text { Ranoides without nd5 } \\
\text { rearrangement }\end{array}$ & $\begin{array}{l}\text { Part of dicroglossids } \\
\text { (Fejervarya and } \\
\text { Hoplobatrachus) }\end{array}$ & 0.3769 & 0.4045 & $\leq 1.00 \times 10^{-7}$ & * \\
\hline 11 & All mt genes & $\begin{array}{l}\text { Non-ranoid } \\
\text { neobatrachians }\end{array}$ & Non- Hyperolius ranoids & Hyperolius & 0.3741 & 0.4048 & $\leq 1.00 \times 10^{-7}$ & * \\
\hline
\end{tabular}


in other ranoids (Nos. 1 and 2 in Table 3, $P=0.688$ and 0.149). Also, the rearranged $n d 5$ in the Babina lineage showed no significant substitution rate difference compared with the non-rearranged ranoid lineages (No. 3, $P=$ 0.102). The duplicated $n d 5$ in Trichobatrachus had a significantly slow substitution rate compared to the nonduplicated ranoid lineages (No. $4, P=0.001$ ), but no significant rate difference was found in the intra-afrobatrachian comparison No. 5, $P=0.658)$. Thus, faster substitution rates than in the non-rearranged lineages were only found in the rearranged $n d 5$ in Rhacophoroidea (No. 6, $P=5 \times 10^{-4}$ ) and part of Dicroglossidae (No. 7, $P \leq 1 \times$ $10^{-7}$ ) and in the duplicated $n d 2$ in Hyperolius (No. 8, $P=4 \times 10^{-7}$ ).

Branch model analysis indicated that the assumed $\omega$ values of $n d 2$ and $n d 5$ on the fast substitution lineages were not substantially different from background values (nd2: background $\omega=0.0285$, Hyperolius branch $\omega=0.0286$, LRT $P=0.96$; $n d 5$ : background $\omega=0.0442$, Rhacophoroidea $\omega=$ 0.0486, Dicroglossidae branch $\omega=0.0450, P=0.96$; $\omega$ values were calculated under four assumed branches $[=$ best model] + fast-evolving branches for each gene). These results indicate that gene duplication does not lead to relaxed purifying pressure on duplicated genes and to fast substitution rates in the mt genomes. Instead, the fast substitution rates of $n d 2$ in the Hyperolius lineage and of $n d 5$ in the Rhacophoroidea and Dicroglossidae lineages seem to simply reflect the substitution rates of the entire mt genomes. In these lineages, all of the mt genes had significantly faster substitution rates than in the non-rearranged lineages (Nos. 9-11), not just the duplicated and rearranged genes. At present, the causes of the higher substitution rates in these rearranged lineages is not obvious. The high $\mathrm{A}+\mathrm{T}$ nucleotide content in the Hyperolius mt genome (64.8\% across all genes, compared with an average of $57.8 \%$ in other ranoid mt genomes; $\chi^{2} P=2 \times 10^{-16}$ ) may be a consequence of the high substitution rates in this genome, or vice versa.

\section{Spatial nucleotide composition bias}

Clinal heterogeneity in the $\mathrm{G}+\mathrm{T}$ nucleotide composition is known to occur in vertebrate mt genes (e.g., $[33,34]$ ). In particular, $\mathrm{H}$-strand encoded genes near the $\mathrm{O}_{\mathrm{L}}$ have high $\mathrm{G}+\mathrm{T}$ content, while those positioned further from the $\mathrm{O}_{\mathrm{L}}$ have low $\mathrm{G}+\mathrm{T}$ content. This clinal variation based on distance from the $\mathrm{O}_{\mathrm{L}}$ can be explained by strand-asymmetric replication, which is unique to animal mt genomes. In this replication system, the synthesis of a nascent $\mathrm{H}$-strand starts at the $\mathrm{H}$-strand replication origin in the CR (from right to left in Figure 1), and the synthesis of the nascent L-strand starts in the $\mathrm{O}_{\mathrm{L}}$ (from left to right in Figure 1) when the nascent $\mathrm{H}$-strand synthesis reaches the $\mathrm{O}_{\mathrm{L}}$ [5]. In this process, the template (old) H-strand results in single-stranded DNA during the L-strand synthesis. The single-stranded DNA is more prone to deamination mutations, leading to $\mathrm{C} \rightarrow \mathrm{T}$ $(\mathrm{U})$ and $\mathrm{A} \rightarrow$ hypoxanthine (pairing with $\mathrm{C}$ ) $\rightarrow \mathrm{G}$ substitutions $[103,104]$. Consequently, the $\mathrm{H}$-strand encoding genes near the $\mathrm{O}_{\mathrm{L}}$ (e.g., co1) have higher $\mathrm{G}+\mathrm{T}$ contents (because of the low frequency of deamination of the template $\mathrm{H}$-strand due to their shorter exposure times as single-strand DNA) than more remote ones.

In Ranoides, all rearranged $n d 5$ genes were more remote from the $\mathrm{O}_{\mathrm{L}}$ compared with their original positions (Figure 1). Also, the duplicated genes in afrobatrachians were further removed from the $\mathrm{O}_{\mathrm{L}}$ than their original copies. However, in almost all cases, the $\mathrm{G}+\mathrm{T}$ contents of these rearranged/duplicated genes did not statistically differ from those of their non-rearranged counterparts. The average $\mathrm{G}+\mathrm{T}$ contents of rearranged and non-rearranged $n d 5$ were 44.3 and $45.2 \%$, respectively $\left(\chi^{2} P=0.24\right)$, those of $n d 2$ were 44.5 and $41.4 \%(P=0.07)$, and those of $12 \mathrm{Srn}$ were 42.3 and $43.9 \%(P=0.48)$. Only the $\mathrm{G}+\mathrm{T}$ contents of $16 S$ rrn differed significantly between rearranged and nonrearranged taxa, but contrary to expectation, the rearranged $16 S \mathrm{rrn}$ (in Breviceps) had low G + T content (40.7 and 43.9\%; $P=0.04$ ).

Broughton and Reneau [34] reported an increase in non-synonymous nucleotide changes (and $\omega$ ) in proportion to distance from $\mathrm{O}_{\mathrm{L}}$ in fish and mammal mt genomes, and they argued that this phenomenon was caused by longterm exposure of the single-stranded $\mathrm{H}$-strand DNA during strand-asymmetric replication. However, as mentioned above, the estimated $\omega$ of the rearranged genes in the rearranged lineages did not differ from those in the nonrearranged lineages. Consequently, changes in $\mathrm{G}+\mathrm{T}$ contents and non-synonymous substitution rates were not observed in the rearranged genes in anuran mt genomes. This result does not mean that strand-asymmetric replication and its accompanying deamination mutations do not occur in ranoid mt genomes. Deamination on the single $\mathrm{H}$-strand is considered the cause of strand-specific nucleotide composition bias generally found in vertebrate $\mathrm{mt}$ genomes $(\mathrm{C}$ rich L-strand, G-rich H-strand [103,104]), and this nucleotide composition heterogeneity was observed between the $\mathrm{L}$ - and $\mathrm{H}$-strands of ranoid mt genomes (average $\mathrm{G}$ content of all $\mathrm{H}$-strand coding genes was $28.3 \%$ on the $\mathrm{H}$-strand and $13.5 \%$ on the L-strand). Rather, a relatively short time since the gene rearrangements (possibly for the lineages of Babina, Breviceps, Hyperolius, and Trichobatrachus), concerted evolution between duplicated genes, and/or strong functional constraints on these mt genes (suggested by very small $\omega$ on anuran mt genes) could have reduced the effects of replication on biased nucleotide substitutions via deamination in duplicated and rearranged $\mathrm{mt}$ genes.

If a specific evolutionary trend exists in the duplicated and/or rearranged genes, the data from these genes could negatively affect phylogenetic reconstruction, for instance, through long-branch attraction and/or 
nucleotide composition heterogeneity. This study found no unique evolutionary trends in these $\mathrm{mt}$ genes, however, supporting the use of duplicated and rearranged $\mathrm{mt}$ genes for phylogenetic inference.

\section{Conclusions}

In this study, we discovered and described highlyrearranged $\mathrm{mt}$ genomes in afrobatrachian frogs. These genomes strongly supported the "first tandem and second non-tandem duplication model" for mitogenomic rearrangements and the "recombination-based model" for concerted evolution of duplicated mitogenomic regions. Our tests also suggested that the rearranged and duplicated $\mathrm{mt}$ genes did not evolve differently, suggesting no disadvantage to employing these genes for phylogenetic inference.

\section{Availability of supporting data}

Detailed information on taxa and genes used in this study is given in Additional file 1. The full sequence data are available in Additional file 2. The aligned datasets (Nucand AA-datasets) used for phylogenetic tree reconstructions are available in Additional file 3. Sequence data and setting files for the molecular dating analysis are available in Additional file 4. The afrobatrachian $\mathrm{O}_{\mathrm{L}}$ regions and possible gene rearrangement pathways leading to the afrobatrachian $\mathrm{WN}-\mathrm{O}_{\mathrm{L}}-\mathrm{ACY}$ trn cluster are illustrated in Additional file 5 .

\section{Additional files}

Additional file 1: Details on taxa and genes used in this study. Taxa and genes used in this study are shown with gene sequence database accession numbers.

Additional file 2: Sequence data used in this study.

Additional file 3: Aligned (Nuc- and AA-) datasets used for phylogenetic tree reconstructions.

Additional file 4: Sequence data and other setting files used in the dating analysis.

Additional file 5: Comparisons of the OL region between afrobatrachians and other neobatrachians and estimated gene rearrangement pathways. Sequences and gene arrangements of the Light-strand replication origin and its neighborhood are shown and compared between afrobatrachians and other neobatrachians. Two distinct gene rearrangement pathways inferred from observed sequence conditions and two alternative rearrangement models are also shown.

\section{Competing interest}

The authors declare that they have no competing interests.

\section{Authors' contributions}

AK performed molecular lab work and analyzed the data. AK and MS wrote the paper. Both authors read and approved the final manuscript.

\section{Acknowledgements}

AK is indebted to Iker Irisarri for providing the aligned datasets and many constructive suggestions regarding data analyses. AK is grateful to Akifumi $S$. Tanabe and Jun Inoue for providing helpful advice about computational issues. We thank Sarah Davis and Takeshi Ebinuma for assistance with species identification of Hyperolius and permission to use the Trichobatrachus photo, respectively. This study was supported by Grants-in Aid for Scientific Research from the Ministry of Education, Culture, Sports, Science, and Technology, Japan (\#19770064 and \#23770088 to AK).

Received: 29 May 2013 Accepted: 13 September 2013 Published: 21 September 2013

\section{References}

1. Wolstenholme DR: Animal mitochondrial DNA: structure and evolution. In Mitochondrial Genomes. Edited by Wolstenholme DR, Jeon KW. New York: Academic Press; 1992:173-216.

2. Boore JL: Survey and summary: animal mitochondrial genomes. Nucleic Acid Res 1999, 27:1767-1780.

3. Jameson D, Gibson AP, Hudelot C, Higgs PG: OGRe: a relational database for comparative analysis of mitochondrial genomes. Nucleic Acids Res 2003, 31:202-206.

4. Kurabayashi A, Sumida M, Yonekawa H, Glaw F, Vences M, Hasegawa M: Phylogeny, recombination, and mechanisms of stepwise mitochondrial genome reorganization in mantellid frogs from Madagascar. Mol Biol Evol 2008, 25:874-891.

5. Clayton DA: Replication of animal mitochondrial DNA. Cell 1982, 28:693-705.

6. Tanaka M, Ozawa T: Strand asymmetry in human mitochondrial mutations. Genomics 1994, 22:327-335.

7. Mindell DP, Sorenson MD, Dimcheff DE: Multiple independent origins of mitochondrial gene order in birds. Proc Natl Acad Sci USA 1998, 95:10693-10697

8. Kumazawa Y, Nishida M: Sequence evolution of mitochondrial tRNA genes and deep-branch animal phylogenetics. J Mol Evol 1993, 37:380-398.

9. San Mauro D, García-París M, Zardoya R: Phylogenetic relationships of discoglossid frogs (Amphibia: Anura: Discoglossidae) based on complete mitochondrial genomes and nuclear genes. Gene 2004, 343:357-366.

10. Mueller RL: Evolutionary rates, divergence dates, and the performance of mitochondrial genes in Bayesian phylogenetic analysis. Syst Biol 2006, 55:289-300.

11. Avise JC: Molecular Markers, Natural History, and Evolution. 2nd edition. Sunderland, Massachusetts: Sinauer Associates Inc; 2004.

12. Sato A, Nakada K, Akimoto M, Ishikawa K, Ono T, Shitara H, Yonekawa H, Hayashi J: Rare creation of recombinant mtDNA haplotypes in mammalian tissues. Proc Natl Acad Sci USA 2005, 102:6057-6062.

13. Inoue JG, Miya M, Tsukamoto K, Nishida M: Evolution of the deep-sea gulper eel mitochondrial genomes: large-scale gene rearrangements originated within the eels. Mol Biol Evol 2003, 20:1917-1924.

14. Boore JL, Brown WM: Mitochondrial genomes and the phylogeny of mollusks. Nautilus 1994, 108(supplement 2):61-78.

15. Moritz C, Dowling TE, Brown WM: Tandem duplications in animal mitochondrial DNAs: variation in incidence and gene content among lizards. Proc Natl Acad Sci USA 1987, 84:7183-7187.

16. Boore JL: The duplication/random loss model for gene rearrangement exemplified by mitochondrial genomes of deuterostome animals. In Computational biology series, vol.1. Edited by Sankoff D, Dordrecht NJ. Netherlands: Kluwer Academic Publishers; 2000:133-147.

17. Thyagarajan B, Padua RA, Campbell C: Mammalian mitochondria possess homologous DNA recombination activity. J Biol Chem 1996, 271:27536-27543.

18. Lunt DF, Hyman BC: Animal mitochondrial DNA recombination. Nature 1997, 387:247.

19. Kajander OA, Rovio AT, Majamaa K, Poulton J, Spelbrink JN, Holt IJ, Karhunen PJ, Jacobs HT: Human mtDNA sublimons resemble rearranged mitochondrial genomes found in pathological states. Hum Mol Genet 2000, 9:2821-2835.

20. Kajander OA, Karhunen PJ, Holt IJ, Jacobs HT: Prominent mitochondrial DNA recombination intermediates in human heart muscle. EMBO reports 2001, 2:1007-1012

21. Kraytsberg Y, Schwartz M, Brown TA, Ebralidse K, Kunz WS, Clayton DA Vissing J, Khrapko K: Recombination of human mitochondrial DNA. Science 2004, 304:981.

22. Rawson PD: Nonhomologous recombination between the large unassigned region of the male and female mitochondrial genomes in the mussel, Mytilus trossulus. J Mol Evol 2005, 61:717-732. 
23. Tsaousis AD, Martin DP, Ladoukakis ED, Posada D, Zouros E: Widespread recombination in published animal mtDNA sequences. Mol Biol Evol 2005, 22:925-933.

24. Dowton M, Campbell NJH: Intramitochondrial recombination: is it why some mitochondrial genes sleep around? Trends Ecol Evol 2001, 16:269-271

25. Endo K, Noguchi $Y$, Ueshima R, Jacobs HT: Novel repetitive structures, deviant protein-encoding sequences and unidentified ORFs in the mitochondrial genome of the brachiopod Lingula anatina. J Mol Evol 2005, 61:36-53.

26. Mueller RL, Boore $J$ : Molecular mechanisms of extensive mitochondrial gene rearrangement in plethodontid salamanders. Mol Biol Evol 2005, 22:2104-2112

27. Kumazawa $Y$, Ota H, Nishida M, Ozawa T: The complete nucleotide sequence of a snake (Dinodon semicarinatus) mitochondrial genome with two identical control regions. Genetics 1998, 150:313-329.

28. San Mauro D, Gower DJ, Zardoya R, Wilkinson M: A hotspot of gene order rearrangement by tandem duplication and random loss in the vertebrate mitochondrial genome. Mol Biol Evol 2006, 23:227-234.

29. Kurabayashi A, Nishitani T, Katsuren S, Oumi S, Sumida M: Mitochondrial genomes and divergence times of crocodile newts: inter-islands distribution of Echinotriton andersoni and the origin of a unique repetitive sequence found in Tylototriton $\mathrm{mt}$ genomes. Genes Genet Syst 2012, 87:39-51.

30. Wagner A: Selection and gene duplication: a view from the genome. Genome Biol 2002, 3:1012.1-1012.3.

31. Jordan IK, Wolf Yl, Koonin EV: Duplicated genes evolve slower than singletons despite the initial rate increase. BMC Evol Biol 2004, 4:22.

32. Kondrashov FA, Rogozin IB, Wolf $Y \mid$, Koonin EV: Selection in the evolution of gene duplications. Genome Biol 2002, 3:8

33. Fonseca MM, Posada D, Harris DJ: Inverted replication of vertebrate mitochondria. Mol Biol Evol 2008, 25:805-808.

34. Broughton RE, Reneau PC: Spatial covariation of mutation and nonsynonymous substitution rates in vertebrate mitochondrial genomes. Mol Biol Evol 2006, 23:1516-1524.

35. Lockhart PJ, Steel MA, Hendy MD, Penny D: Recovering evolutionar y trees under a more realistic model of sequence evolution. Mol Biol Evol 1994, 11:605-612.

36. Philippe $H$, Germot A: Phylogeny of eukaryotes based on ribosomal RNA: long-branch attraction and models of sequence evolution. Mol Biol Evol 2000, 17:830-834.

37. Rosenberg MS, Kumar S: Heterogeneity of nucleotide frequencies among evolutionary lineages and phylogenetic inference. Mol Biol Evol 2003, 20:610-621.

38. Irisarri I, San Mauro D, Abascal F, Ohler A, Vences M, Zardoya R: The origin of modern frogs (Neobatrachia) was accompanied by acceleration in mitochondrial and nuclear substitution rates. BMC Genomics 2012, 13:626.

39. Duellman WE: Anura (Frogs and toads). In Grzimek's Animal Life Encyclopedia (Vol. 6) Amphibians, 2nd ed. Edited by Hutchins M, Duellman WE, Schlager N. Farmington Hills, Canada: Gale Group; 2003:61-68.

40. Frost DR, Grant T, Faivovich J, et al: The amphibian tree of life. Bull Amer Mus Natl Hist 2006, 297:1-371.

41. Frost DR: Amphibian species of the world: an online reference. Version $5.6 \mathrm{New}$ York, USA: American Museum of Natural History; 2013. http://research.amnh. org/vz/herpetology/amphibia/.

42. Amphibiaweb: A database of information on amphibian biology, conservation and taxonomy, with specie life history, distribution, photos, sound recordings and habitat. Berkley, California, USA; 2013. http://amphibiaweb.org/.

43. Irisarri I, San Mauro D, Green DM, Zardoya R: The complete mitochondrial genome of the relict frog Leiopelma archeyi: insights into the root of the frog Tree of Life. Mitochondrial DNA 2010, 21:173-182.

44. Sumida M, Kanamori Y, Kaneda H, Kato Y, Nishioka M, Hasegawa M, Yonekawa $\mathrm{H}$ : Complete nucleotide sequence and gene rearrangement of the mitochondrial genome of the Japanese pond frog Rana nigromaculata. Genes Genet Syst 2001, 76:311-325.

45. Zhang P, Zhou H, Liang D, Liu YF, Chen YQ, Qu LH: Mitogenomic perspectives on the origin and phylogeny of living amphibians. Syst BiOl 2005, 54:391-400.

46. Igawa $T$, Kurabayashi A, Usuki C, Fujii T, Sumida M: Complete mitochondrial genomes of three neobatrachian anurans: a case study of divergence time estimation using different data and calibration settings. Gene 2008 407:116-129.
47. Kurabayashi A, Yoshikawa N, Sato N, Hayashi Y, Oumi S, Fujii T, Sumida M: Complete mitochondrial DNA sequence of the endangered frog Odorrana ishikawae (family Ranidae) and unexpected diversity of $\mathrm{mt}$ gene arrangements in ranids. Mol Phylogenet Evol 2010, 56:543-553.

48. Alam MS, Kurabayashi A, Hayashi Y, Sano N, Khan MMR, Fujii T, Sumida M: Complete mitochondrial genomes and novel gene rearrangements in two dicroglossid frogs, Hoplobatrachus tigerinus and Euphlyctis hexadactylus, from Bangladesh. Genes Genet Syst 2010, 85:219-232.

49. Kakehashi R, Kurabayashi A, Oumi S, Katsuren S, Hoso M, Sumida M: Mitochondrial genomes of Japanese Babina frogs (Ranidae, Anura): unique gene arrangements and the phylogenetic position of genus Babina. Genes Genet Syst 2013, 88:59-67.

50. Van der Meijden A, Vences M, Meyer A: Novel phylogenetic relationships of the enigmatic brevicipitine and scaphiophrynine toads as revealed by sequences from the nuclear Rag-1 gene. Proc Bio/ Sci 2004, 271:378-381.

51. Roelants K, Gower DJ, Wilkinson M, Loader SP, Biju SD, Guillaume K, Moriau $\mathrm{L}$, Bossuyt F: Global patterns of diversification in the history of modern amphibians. Proc Natl Acad Sci USA 2007, 104:887-892.

52. Pyron RA, Wiens JJ: A large-scale phylogeny of Amphibia including over 2800 species, and a revised classification of extant frogs, salamanders, and caecilians. Mol Phylogenet Evol 2011, 61:543-583.

53. Kurabayashi A, Sumida M: PCR Primers for the Neobatrachian Mitochondrial Genome. Current Herpetol 2009, 28:1-11.

54. Henikoff S: Ordered deletions for DNA sequencing and in vitro mutagenesis by polymerase extension and exonuclease III gapping of circular templates. Nucleic Acids Res 1990, 18:2961-2966.

55. Shadel GS, Clayton DA: Mitochondrial DNA maintenance in vertebrates. Annu Rev Biochem 1997, 66:409-435.

56. Crottini A, Madsen O, Poux C, Strauß A, Vieites DR, Vences M: Vertebrate time-tree elucidates the biogeographic pattern of a major biotic change around the K-T boundary in Madagascar. Proc Natl Acad Sci USA 2012, 109:5358-5363.

57. San Mauro D: A multilocus timescale for the origin of extant amphibians. Mol Phylogenet Evol 2010, 56:554-561.

58. Roelants K, Bossuyt F: Archaeobatrachian paraphyly and pangaean diversification of crown-group frogs. Syst Biol 2005, 54:111-126.

59. Katoh $\mathrm{K}$, Kuma $\mathrm{K}$, Toh H, Miyata T: MAFFT version 5: improvement in accuracy of multiple sequence alignment. Nucleic Acids Res 2005, 33:511-518.

60. Abascal F, Zardoya R, Telford MJ: TranslatorX: multiple alignment of nucleotide sequences guided by amino acid translations. Nucleic Acids Res 2010, 38:W7-W13.

61. Castresana J: Selection of conserved blocks from multiple alignments for their use in phylogenetic analysis. Mol Biol Evol 2000, 17:540-552.

62. Katoh K, Toh H: Recent developments in the MAFFT multiple sequence alignment program. Brief Bioinform 2008, 9:286-298.

63. Hoegg $S$, Vences M, Brinkmann $H$, Meyer A: Phylogeny and comparative substitution rates of frogs inferred from sequences of three nuclear genes. Mol Biol Evol 2004, 21:1188-1200.

64. Gissi C, San Mauro D, Pesole G, Zardoya R: Mitochondrial phylogeny of Anura (Amphibia): a case study of congruent phylogenetic reconstruction using amino acid and nucleotide characters. Gene 2006, 366:228-237.

65. Akaike $\mathrm{H}$ : Information theory and an extention of the maximum likelihood principle. In Proceedings of the 2nd international symposium on information theory. Edited by Petrov BN, Caski F. Budapest: Akadimiai Kiado; 1973:267-281.

66. Lanfear R, Calcott B, Ho SYW, Guindon S: PartitionFinder: combined selection of partitioning schemes and substitution models for phylogenetic analyses. Mol Biol Evol 2012, 29:1695-1701.

67. Steel MA, Lockhart PJ, Penny D: Confidence in evolutionary trees from biological sequence data. Nature 1993, 364:440-442.

68. Tanabe AS: Phylogears version 2-2.0. ; 2008. http://www.fifthdimension.jp/.

69. Phillips MJ, Penny D: The root of the mammalian tree inferred from whole mitochondrial genomes. Mol Phylogenet Evol 2003, 28:171-185.

70. Phillips MJ, Delsuc F, Penny D: Genome-scale phylogeny and the detection of systematic biases. Mol Biol Evol 2004, 21:1455-1458.

71. Stamatakis A: RAxML-VI-HPC: maximum likelihood-based phylogenetic analyses with thousands of taxa and mixed models. Bioinformatics 2006, 22:2688-2690. 
72. Tanabe AS: MrBayes5D; 2008. http://www.fifthdimension.jp/.

73. Ronquist F, Huelsenbeck JP: MRBAYES 3: Bayesian phylogenetic inference under mixed models. Bioinformatics 2003, 19:1572-1574.

74. Tanabe AS: Kakusan4 and Aminosan: two programs for comparing nonpartitioned, proportional, and separate models for combined molecular phylogenetic analyses of multilocus sequence data. Mol Ecol Res 2011, 11:914-921.

75. Stamatakis A, Blagojevic F, Nikolopoulos D, Antonopoulos C: Exploring new search algorithms and hardware for phylogenetics: RAxML meets the IBM cell. J VLSI Signal Proc 2007, 48:271-286.

76. Rambaut A, Drummond AJ: Tracer v. 1.5; 2009. http://tree.bio.ed.ac.uk/ software/tracer/.

77. Yang Z: PAML 4: Phylogenetic analysis by maximum likelihood. $\mathrm{Mol}$ Biol Evol 2012, 24:1586-1591

78. Sarich VM, Wilson AC: Generation time and genomic evolution in primates. Science 1973, 179:1144-1147.

79. Robinson RM, Huchon D: RRTree: relative-rate tests between groups of sequences on a phylogenetic tree. Bioinformatics 2000, 16:296-297.

80. Li P, Bousquet J: Relative rate test for nucleotide substitutions between two lineages. Mol Biol Evol 1992, 9:1185-1189.

81. Robinson M, Gouy M, Gautier C, Mouchiroud D: Sensitivity of the relativerate test to taxonomic sampling. Mol Biol Evol 1998, 15:1091-1098.

82. Kimura M: A simple method for estimating evolutionary rates of base substitutions through comparative studies of nucleotide sequences. J Mol Evol 1980, 16:111-120.

83. Yang Z: Computational molecular evolution. New York: Oxford University Press; 2006.

84. Buschiazzo E, Ritland C, Bohlmann J, Ritland K: Slow but not low: genomic comparisons reveal slower evolutionary rate and higher $\mathrm{dN} / \mathrm{dS}$ in conifers compared to angiosperms. BMC Evol Biol 2012, 12:8.

85. Blommers-Schlösser RMA: Observations on the larval development of some Malagasy frogs, with notes on their ecology and biology (Anura: Dyscophinae, Scaphiophryninae and Cophylinae). Beaufortia Amsterdam 1975, 24:7-26.

86. Blommers-Schlösser RMA: Systematic relationships of the Mantellinae Laurent 1946 (Anura Ranoidea). Ethol Ecol Evol 1993, 5:199-218.

87. Ford LS: The phylogenetic position of the dart-poison frogs (Dendrobatidae) among anurans - an examination of the competing hypotheses and their characters. Ethol Ecol Evol 1993, 5:219-231.

88. Emerson SB, Inger RF, Iskandar D: Molecular systematics and biogeography of the fanged frogs of Southeast Asia. Mol Phylogenet Evol 2000, 16:131-142.

89. Kurabayashi A, Matsui M, Belabut DM, Yong HS, Ahmad N, Sudin A, Kuramoto M, Hamidy A, Sumida M: From Antarctica or Asia? new colonization scenario for Australian-New Guinean narrow mouth toads suggested from the findings on a mysterious genus Gastrophrynoides. BMC Evol Biol 2011, 11:175.

90. Bossuyt F, Roelants K: Frogs and toads (Anura). In Timetree of life. Edited by Hedges SB, Kumar S. New York: Oxford University Press; 2009:357-364.

91. Van Bocxlaer I, Roelants K, Biju SD, Nagaraju J, Bossuyt F: Late Cretaceous vicariance in Gondwanan amphibians. PLoS One 2006, 1:e74

92. Van der Meijden A, Vences M, Hoegg S, Boistel R, Channing A, Meyer A: Nuclear gene phylogeny of narrow-mouthed toads (Family: Microhylidae) and a discussion of competing hypotheses concerning their biogeographical origins. Mol Phylogenet Evol 2007, 44:1017-1030.

93. Futuyma DJ: A history of life on earth. In Evolution. 2nd edition. Edited by Futuyma DJ. Sunderland, Massachusetts: Sinauer associates; 2005:91-116.

94. Fujita MK, Boore $J \mathrm{~L}$, Moritz C: Multiple origins and rapid evolution of duplicated mitochondrial genes in parthenogenetic geckos (Heteronotia binoei; Squamata, Gekkonidae). Mol Biol Evol 2007, 24:2775-2786.

95. Lupi R, de Meo PDO, Picardi E, D'Antonio M, Paoletti D, Castrignanò T, Pesole G, Gissi C: MitoZoa: a curated mitochondrial genome database of metazoans for comparative genomics studies. Mitochondrion 2010, 10:192-199.

96. Yokobori S, Fukuda N, Nakamura M, Aoyama T, Oshima T: Long-term conservation of six duplicated structural genes in cephalopod mitochondrial genomes. Mol Biol Evol 2004, 21:2034-2046.

97. Hoffmann RJ, Boore JL, Brown WM: A novel mitochondrial genome organization for the blue mussel. Mytilus edulis. Genetics 1992, 131:397-412.
98. Kurabayashi A, Ueshima R: Complete sequence of the mitochondrial DNA of the primitive opisthobranch gastropod Pupa strigosa: systematic implication of the genome organization. Mol Biol Evol 2000, 17:266-277.

99. Yokobori S, Oshima T, Wada H: Complete nucleotide sequence of the mitochondrial genome of Doliolum nationalis with implications for evolution of urochordates. Mol Phylogenet Evol 2005, 34:273-283.

100. Noguchi Y, Endo K, Tajima F, Ueshima R: The mitochondrial genome of the brachiopod Laqueus rubellus. Genetics 2000, 155:245-259.

101. Shao R, Dowton M, Murrell A, Barker SC: Rates of gene rearrangement and nucleotide substitution are correlated in the mitochondrial genomes of insects. Mol Biol Evol 2003, 20:1612-1619.

102. Xu W, Jameson D, Tang B, Higgs PG: The relationship between the rate of molecular evolution and the rate of genome rearrangement in animal mitochondrial genomes. J Mol Evol 2006, 63:375-392.

103. Frederico LA, Kunkel TA, Shaw BR: A sensitive genetic assay for the detection of cytosine deamination: determination of rate constants and the activation energy. Biochemistry 1990, 29:2532-2537.

104. Lindahl T: Instability and decay of the primary structure of DNA. Nature 1993, 362:709-715.

doi:10.1186/1471-2164-14-633

Cite this article as: Kurabayashi and Sumida: Afrobatrachian mitochondrial genomes: genome reorganization, gene rearrangement mechanisms, and evolutionary trends of duplicated and rearranged genes. BMC Genomics 2013 14:633.

\section{Submit your next manuscript to BioMed Central and take full advantage of:}

- Convenient online submission

- Thorough peer review

- No space constraints or color figure charges

- Immediate publication on acceptance

- Inclusion in PubMed, CAS, Scopus and Google Scholar

- Research which is freely available for redistribution 